\title{
Heat transfer during drop impact on a heated foil
}

\author{
Tatiana Ponomarenko ${ }^{1,2}$, and Aleksey Safonov ${ }^{1,3}$ \\ ${ }^{1}$ Kutateladze Institute of Thermophysics SB RAS, 630090, Novosibirsk, Russia \\ ${ }^{2}$ Novosibirsk State Technical University, 630073, Novosibirsk, Russia \\ ${ }^{3}$ Novosibirsk State University, 630090, Novosibirsk, Russia
}

\begin{abstract}
The heat transfer during impact, evaporation and dynamics of the water drop on the heated thin constantan foil have been studied. The function of diameter versus time is constructed.
\end{abstract}

\section{Introduction}

The growth of the number of transistors in one processor leads to an increase in the thermal power dissipated by the processor. So, cooling systems that are currently used are not effective enough.

A cooling system with sprays is promising, when the flow is directed to the heating element, as a result, a liquid film is formed on surface that partially or completely wetted. Drop phenomena's (evaporation, dynamics, wetting etc.) are widely studding [1-5]. Heat transfer and deformation in this case are determined by several factors: the inertia of the flying drops, the surface tension, the acceleration value, the wettability, the geometry of the working surface, the surface tension of the liquid, and its volatility [6;7]. The spray cooling curve has been observed by many researchers to be quite linear at low superheats, indicating that single-phase convection is the primary heat transfer mechanism. Pautsch and Shedd [8] verified this using a novel technique to measure the local film thickness produced by sprays.

\section{Experimental setup}

The scheme and photo of the experimental setup are shown in Fig. 1. A constantan foil $(\mathrm{CuNi})$ of the thickness of $25 \mu \mathrm{m}$, size of $80 \times 35 \mathrm{~mm} 2$ and heat conductivity $\lambda$ of $23 \mathrm{~W} / \mathrm{mK}$ is soldered to the two brass electrodes (3). Our foil was coated with thin fluoropolymer film by HWCVD method. The method and experimental setup were described in [8]. The thickness of film is $100 \mathrm{~nm}$. The electrodes are connected to the electrical power supply (2) - TTi QPX 1200L. The temperature of the foil surface is measured by IR camera Titanium 570M (6) with help of gold mirror (1). The high-speed camera FastVideo 500M (5) is used to observe a drop (4) from top view. The $1 \mathrm{ml}$ syringe (7) with water is used to inject a drop from height about $100 \mathrm{~mm}$ to the foil. The heat transfer coefficient from the foil surface to surrounding air is about $25 \mathrm{~W} / \mathrm{m} 2 \mathrm{~K}$. These measurements were performed without droplets on the foil surface with the same heat flux. 

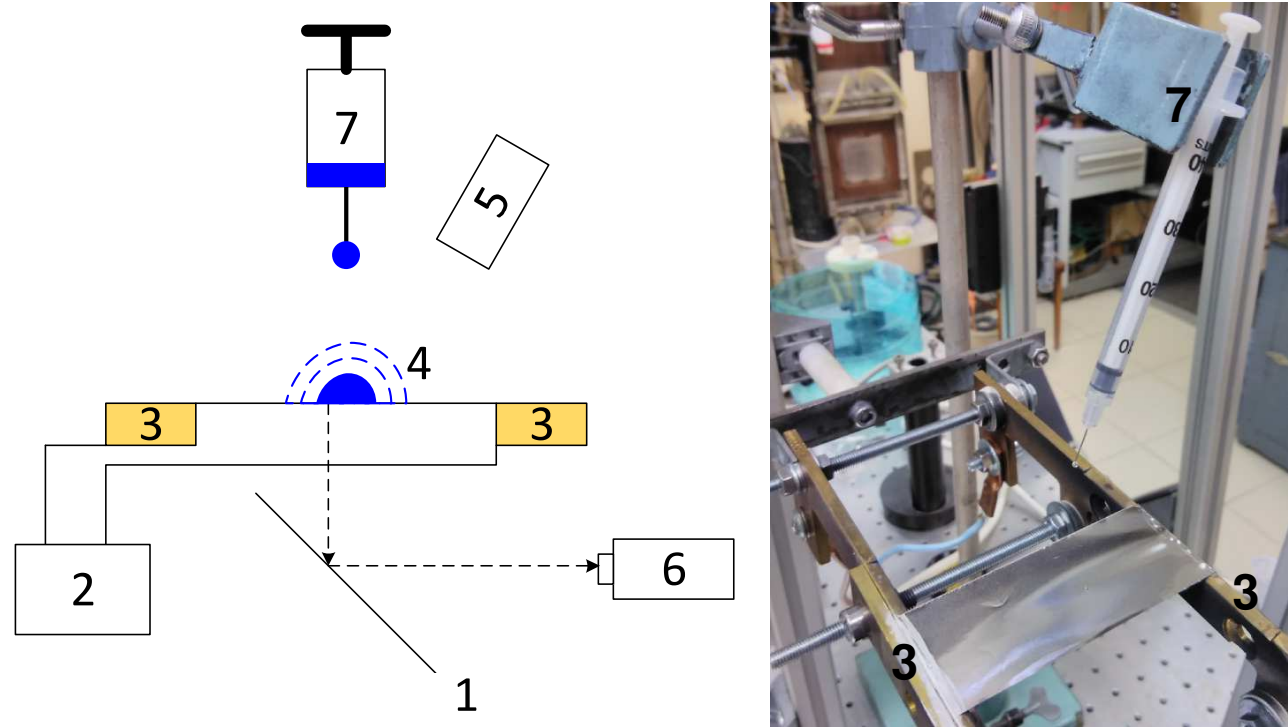

Figure 1. Scheme and photo of the experimental setup for the study of heat transfer and the dynamics of the evaporating liquid drop on the heated foil, where 1 - gold mirror, 2 - power source, 3 - brass electrodes with a constantan-foil stretched between them, 4 - evaporating drop of liquid, 5 - highspeed camera FastVideo 500M, 6 - IR scanner Titanium 570M.

\section{Results and discussion}

The IR-pictures from bottom side of foil and photo of drop $(0.86 \mu l)$ during impact on the foil for different time moment are demonstrated in Fig. 2 and 3. The diameter of the drop is shown in Fig. 4. At the first 20 seconds drop diameter is slightly increased due to spreading of the drop on the foil but then decreasing during 13 minutes due to evaporation. These data will be used now to solve Cauchy problem for non-stationary heat transfer equation in thin constantan foil to find heat flux near with contact line of this drop with boundary conditions - constant heat flux and temperature distribution for bottom side of foil for different moment of time. 

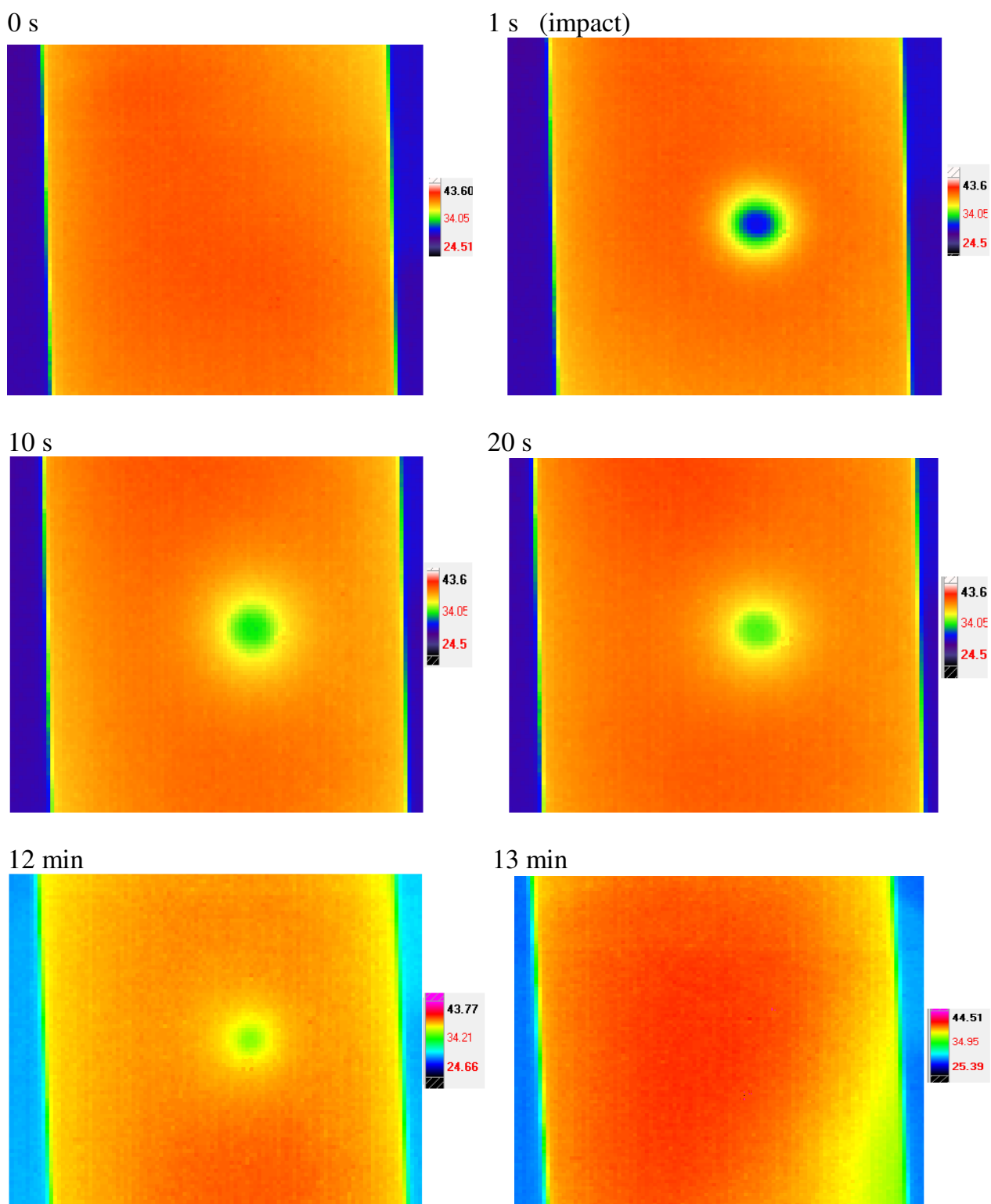

13 min

Figure 2. Thermal images of water drop $0.86 \mu l, \mathrm{q}_{\mathrm{s}}=543 \mathrm{~W} / \mathrm{m}^{2}$ 
$0 \mathrm{~s}$

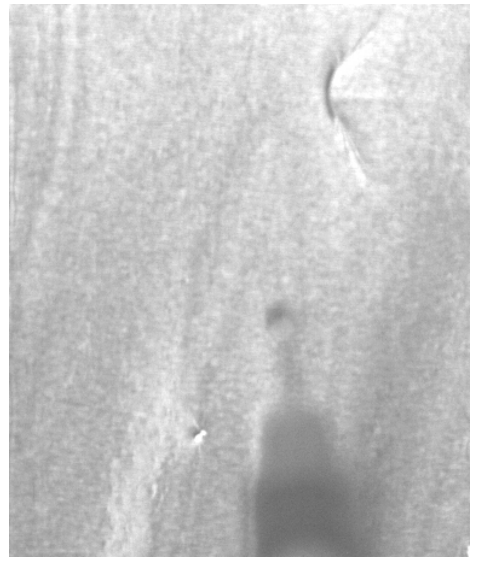

$10 \mathrm{~s}$

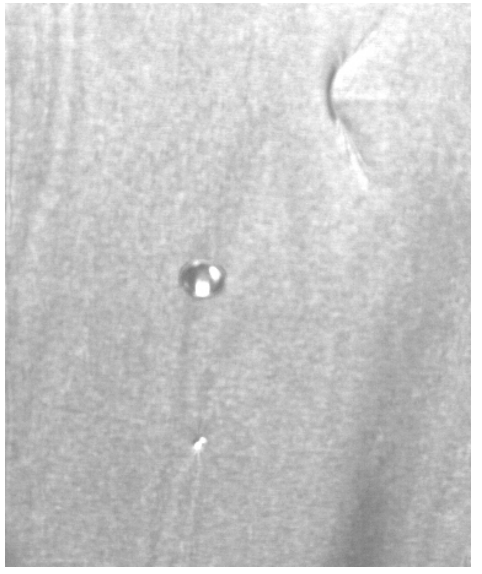

$12 \min$

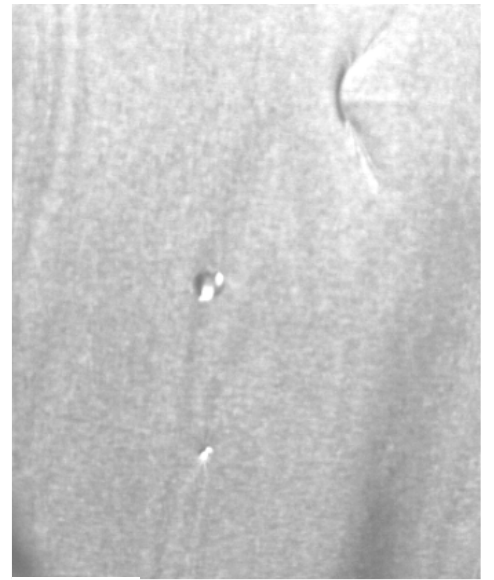

Figure 3. Thermal images of water drop $0.86 \mu \mathrm{l}, \mathrm{q}_{\mathrm{s}}=543 \mathrm{~W} / \mathrm{m}^{2}$
$1 \mathrm{~s}$ (impact)

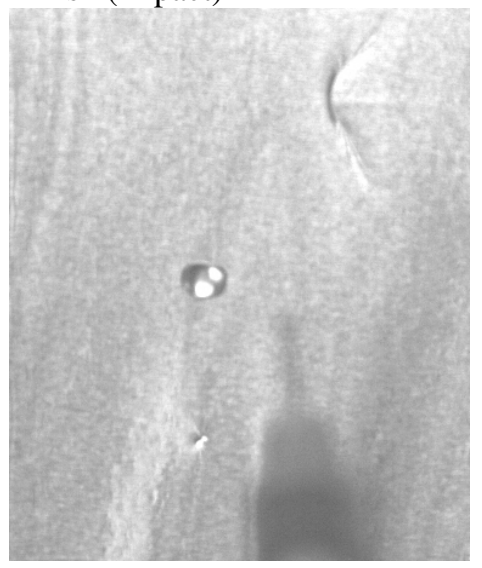

$20 \mathrm{~s}$

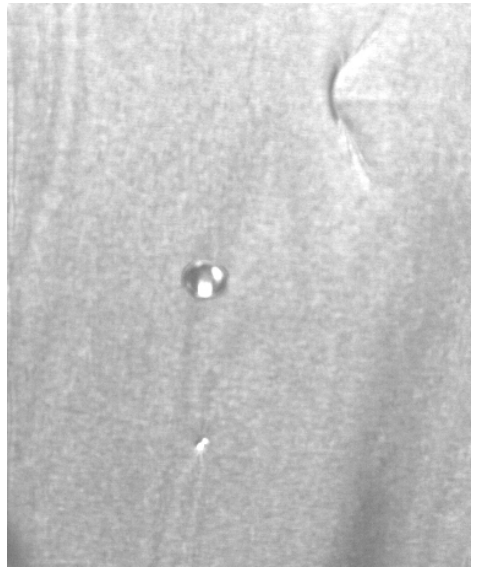

$13 \mathrm{~min}$

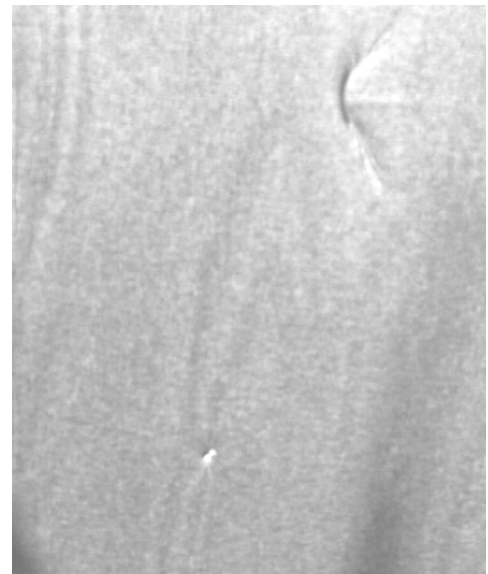




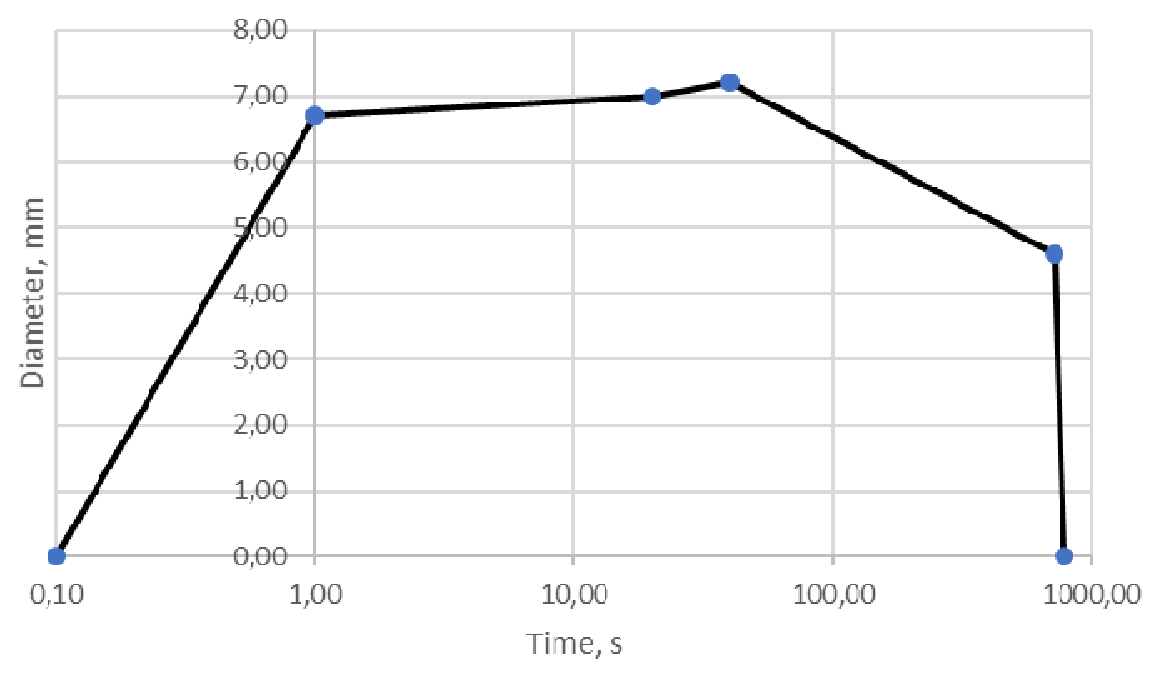

Figure 4. Diameter of the drop on the foil versus time.

\section{Conclusions}

The first test experiments with a pulsating heat pipe with water were carried out. It is established that pulsations begin when the tube is heated. In the future, it is planned to use sapphire tubes to determine the water temperature

The reported study was funded by RFBR according to the research project № 18-58-45016.

\section{References}

1. V.V. Cheverda, A.L. Karchevsky, I.M. Marchuk, O.A. Kabov, Thermophysics and Aeromechanics 24(5), 803-806, 2017

2. V.Yu.Borodulin, V.N.Letushko, M.I. Nizovtsev, A.N.Sterlyagov, International Journal of Heat and Mass Transfer, 109, 609-618, 2017.

3. S.Y. Misyura, R.S. Volkova, A.S., Colloids and Surfaces A, 559, 275-283, 2018.

4. V Y Borodulin, V N Letushko, M I Nizovtsev and A N Sterlyagov, Journal of Physics: Conference Series, 754, 032018, 2016

5. O. Kyriopoulos, I. Roisman, P. Stephan, C. Tropea, Microgravity Science and Technology, XIX (3/4), 151-154, (2007).

6. I. V. Roisman, T. Gambaryan-Roisman, O. Kyriopoulos, P. Stephan and C. Tropea, Phys. Rev. E., 76 (2), 26302-1 - 26302-9, (2007).

7. A.G. Pautsch, T.A. Shedd, International Journal of Heat and Mass Transfer, 49, 2610 2618, (2006).

8. A Safonov, V Sulyaeva, E Gatapova, S Starinskiy, N Timoshenko and O Kabov Thin Solid Films, 653, 165, 2018 